\title{
Preventable Health Behaviors, COVID-19 Severity Perceptions, and Vaccine Uptake in Traditional Medicare and Medicare Advantage: a Survey-Based Study
}

J Gen Intern Med 36(6):1837-40

DOI: $10.1007 / \mathrm{s} 11606-021-06801-\mathrm{w}$

(c) Society of General Internal Medicine 2021

$\mathrm{U}$ nlike fee-for-service traditional Medicare (TM), Medicare Advantage (MA) plans are paid a fixed amount for each enrollee and therefore are incentivized to keep their enrollees healthy by prioritizing prevention and care management. ${ }^{1}$ This suggests that MA plans may better respond to coronavirus disease 2019 (COVID-19)-related risks by providing information and education towards COVID-19 preventive practices. In this study, we examined whether there were differences in preventable health behaviors, perceptions of COVID-19 severity, and the likelihood of COVID-19 vaccine uptake (if available) between TM and MA enrollees.

\section{METHODS}

We used data from the Medicare Current Beneficiary Survey Fall 2020 COVID-19 Supplement, collected via phone interviews between October and November $2020 .^{2}$ We identified Medicare beneficiaries older than 65 years with full-year enrollment in TM or MA. This study used deidentified, publicly available data, and thus was considered not human subjects research.

We included three types of outcomes. The first included 16 measures of preventable health behaviors. Beneficiaries were asked to answer "yes" or "no" for each health behavior. The second included three measures of perceptions of COVID-19 severity. Beneficiaries were asked to rate the following statements using a 5-point scale: "Coronavirus is more contagious than the flu," "Coronavirus is more deadly than the flu," and "it is important for everyone to take precautions to prevent the spread of the Coronavirus, even if they are not in a high-risk group." We categorized responses into two levels: agreed versus not-agreed (neutral or disagreed). The last included the likelihood of COVID-19 vaccine uptake (if available),

Received February 1, 2021

Accepted April 1, 2021

Published online April 12, 2021 for which beneficiaries answered on a 5-point scale. We categorized answers into two levels: likely versus unlikely (including unsure). Our primary explanatory variable was MA enrollment.

Evidence suggests that MA enrollees tend to be healthier than TM enrollees, indicating that a direct comparison between TM and MA enrollees is potentially biased. ${ }^{3}$ To address selective enrollment, we computed the inverse probability of treatment weighting (IPTW) as a propensity for enrolling in MA based on the variables described above. ${ }^{4}$ To examine differences in the outcomes between TM and MA enrollees, we conducted logistic regression after controlling for demographic, socioeconomic, health status characteristics, the primary source of COVID-19 information, and the date of interview, and applied the IPTW. Then, we calculated the adjusted mean values of the outcomes for TM and MA enrollees while holding constant all other variables except the variable of interest. Next, we examined the difference in these adjusted outcomes among MA enrollees relative to TM enrollees.

\section{RESULTS}

We included $2541 \mathrm{TM}$ enrollees and 1807 MA enrollees in 2020 (Table 1). Several differences existed in weighted sample characteristics between TM and MA enrollees, but they decreased after applying the IPTW.

Our IPTW-adjusted analyses showed no or marginal differences in preventable health behaviors, perceptions of COVID19 severity, and the likelihood of COVID-19 vaccine uptake between TM and MA enrollees (Table 2). A statistically significant difference was observed only in three outcomes: compared to TM enrollees, MA enrollees had statistically significantly higher rates of wearing facemask $(0.8$ percentage point difference [95\% CI: 0.1-1.4]), avoiding large groups of people (3.1 percentage point difference [95\% CI: 1.6-4.7]), and agreeing that all should take COVID-19 precautions (1.2 percentage point difference [95\% CI: 0.1-2.3]).

\section{DISCUSSION}

We found few differences in preventive responses to COVID19-related risks between TM and MA enrollees. This aligns 
Table 1 Sample Characteristics Between TM and MA Enrollees

\begin{tabular}{|c|c|c|c|c|c|c|}
\hline & \multicolumn{2}{|l|}{$N(\%)$} & \multicolumn{2}{|c|}{$\begin{array}{l}\text { Weighted \% without } \\
\text { IPTW* }\end{array}$} & \multicolumn{2}{|c|}{ Weighted \% with IPTW } \\
\hline & $\begin{array}{l}\text { TM enrollees } \\
(N=\mathbf{2 4 1 2})\end{array}$ & $\begin{array}{l}\text { MA enrollees } \\
(N=1545)\end{array}$ & $\begin{array}{l}\text { TM } \\
\text { enrollees }\end{array}$ & $\begin{array}{l}\text { MA } \\
\text { enrollees }\end{array}$ & $\begin{array}{l}\text { TM } \\
\text { enrollees }\end{array}$ & $\begin{array}{l}\text { MA } \\
\text { enrollees }\end{array}$ \\
\hline \multicolumn{7}{|l|}{ Covariates } \\
\hline \multicolumn{7}{|l|}{ Age } \\
\hline 65-74 years & $1216(47.9)$ & $835(46.2)$ & 66.2 & 60.9 & 64.1 & 64.2 \\
\hline $75+$ years & $1325(52.1)$ & $972(53.8)$ & 33.8 & 39.1 & 35.9 & 35.8 \\
\hline \multirow{2}{*}{\multicolumn{7}{|c|}{ Race/ethnicity }} \\
\hline & & & & & & \\
\hline Non-Hispanic white & $2154(84.8)$ & $1334(73.8)$ & 82.7 & 74.5 & 80.1 & 79.5 \\
\hline Hispanic & $142(5.6)$ & $181(10.0)$ & 7.1 & 10.3 & 7.8 & 8.7 \\
\hline Non-Hispanic black & $127(5.0)$ & $208(11.5)$ & 4.8 & 9.8 & 6.3 & 6.7 \\
\hline Other & $118(4.6)$ & $84(4.6)$ & 5.4 & 5.4 & 5.8 & 5.0 \\
\hline \multicolumn{7}{|l|}{ Income } \\
\hline$\$ 25,000$ or more & $496(19.5)$ & $629(34.8)$ & 16.1 & 32.0 & 21.7 & 21.5 \\
\hline Less than $\$ 25,000$ & $2045(80.5)$ & $1178(65.2)$ & 83.9 & 68.0 & 78.3 & 78.5 \\
\hline Dual eligibility for Medicare and & $129(5.1)$ & $262(14.5)$ & 3.9 & 12.6 & 7.1 & 7.0 \\
\hline \multicolumn{7}{|l|}{ Medicaid } \\
\hline Residence of urban areas & $1884(74.1)$ & $1534(84.9)$ & 78.5 & 87.5 & 81.5 & 80.2 \\
\hline \multicolumn{7}{|l|}{ US census regions } \\
\hline Northeast & $482(19.0)$ & $326(18.0)$ & 19.0 & 17.4 & 18.6 & 18.1 \\
\hline Midwest & $618(24.3)$ & $432(23.9)$ & 22.8 & 22.9 & 21.9 & 25.8 \\
\hline South & $938(36.9)$ & $615(34.0)$ & 37.3 & 34.1 & 37.9 & 33.2 \\
\hline West & $503(19.8)$ & $434(24.0)$ & 20.9 & 25.6 & 21.6 & 22.9 \\
\hline $\begin{array}{l}\text { Use of other language at home other } \\
\text { than English }\end{array}$ & $165(6.5)$ & $239(13.2)$ & 6.6 & 12.8 & 8.8 & 8.7 \\
\hline Having a particular place for medical & $2348(92.4)$ & $1666(92.2)$ & 91.9 & 92.0 & 91.9 & 91.7 \\
\hline \multirow{2}{*}{\multicolumn{7}{|c|}{$\begin{array}{l}\text { Primary sources of COVID-19 infor- } \\
\text { mation }\end{array}$}} \\
\hline & & & & & & \\
\hline Traditional news sources & $1371(54.0)$ & $993(55.0)$ & 50.6 & 53.7 & 51.7 & 52.3 \\
\hline Comments/guidance from govern- & $31(1.2)$ & $23(1.3)$ & 1.4 & 1.2 & 1.3 & 1.3 \\
\hline \multicolumn{7}{|l|}{ ment officials } \\
\hline Social media & $257(10.1)$ & $146(8.1)$ & 11.0 & 9.4 & 10.5 & 10.5 \\
\hline Other webpages/internet & $177(7.0)$ & $102(5.6)$ & 8.9 & 6.8 & 8.1 & 8.0 \\
\hline Friends or family members & $178(7.0)$ & $156(8.6)$ & 5.9 & 7.8 & 6.8 & 6.8 \\
\hline Health care providers & $527(20.7)$ & $387(21.4)$ & 22.2 & 21.2 & 21.6 & 21.2 \\
\hline Self-reported health conditions & & & & & & \\
\hline Hypertension & $1681(66.2)$ & $1231(68.1)$ & 62.3 & 65.7 & 63.5 & 63.4 \\
\hline Myocardial infarction & $236(9.3)$ & $196(10.8)$ & 7.7 & 10.3 & 8.6 & 8.5 \\
\hline Congestive heart failure & $153(6.0)$ & $109(6.0)$ & 4.8 & 5.5 & 5.1 & 5.5 \\
\hline Stroke & $219(8.6)$ & $150(8.3)$ & 7.6 & 8.2 & 7.9 & 7.8 \\
\hline High cholesterol & $1756(69.1)$ & $1269(70.2)$ & 67.1 & 68.4 & 67.2 & 66.8 \\
\hline Cancer & $577(22.7)$ & $401(22.2)$ & 20.8 & 20.9 & 20.9 & 20.9 \\
\hline Alzheimer's disease/dementia & $32(1.3)$ & $32(1.8)$ & 1.0 & 1.3 & 1.0 & 1.1 \\
\hline Depression & $498(19.6)$ & $402(22.2)$ & 20.9 & 22.5 & 21.4 & 21.7 \\
\hline Osteoporosis & $519(20.4)$ & $395(21.9)$ & 20.1 & 21.6 & 20.6 & 20.8 \\
\hline Broken hip & $86(3.4)$ & $60(3.3)$ & 2.6 & 3.0 & 2.8 & 2.8 \\
\hline Emphysema/asthma/COPD & $467(18.4)$ & $311(17.2)$ & 17.7 & 17.4 & 17.6 & 17.9 \\
\hline Diabetes & $802(31.6)$ & $624(34.5)$ & 31.6 & 34.7 & 32.6 & 33.0 \\
\hline Weak immune system & $407(16.0)$ & $280(15.5)$ & 16.9 & 15.5 & 16.4 & 16.8 \\
\hline Smoking status & & & & & & \\
\hline Current smoker & $201(7.9)$ & $153(8.5)$ & 9.5 & 8.9 & 9.2 & 9.0 \\
\hline Former smoker & $1314(51.7)$ & $843(46.7)$ & 49.0 & 45.1 & 48.1 & 48.5 \\
\hline Never smoked & $1026(40.4)$ & $811(44.9)$ & 41.5 & 46.0 & 42.7 & 42.5 \\
\hline Interview date & & & & & & \\
\hline Week of October 4, 2020 & $508(20.0)$ & $349(19.3)$ & 20.2 & 18.5 & 19.5 & 19.8 \\
\hline Week of October 11,2020 & $663(26.1)$ & $467(25.8)$ & 25.2 & 25.9 & 25.5 & 25.3 \\
\hline Week of October 18, 2020 & $472(18.6)$ & $351(19.4)$ & 20.5 & 19.6 & 19.9 & 19.7 \\
\hline Week of October 25, 2020 & $421(16.6)$ & $292(16.2)$ & 15.8 & 16.6 & 16.4 & 16.2 \\
\hline Week of November 1,2020 & $310(12.2)$ & $233(12.9)$ & 11.9 & 12.9 & 12.4 & 12.6 \\
\hline November 8 to 15,2020 & $167(6.6)$ & $115(6.4)$ & 6.4 & 6.5 & 6.4 & 6.5 \\
\hline Outcomes & & & & & & \\
\hline Preventable health behaviors & & & & & & \\
\hline Wash hands & $2466(97.0)$ & 1751 (96.9) & 97.1 & 97.0 & 97.0 & 97.1 \\
\hline Use sanitizer & $2372(93.3)$ & $1682(93.1)$ & 93.6 & 93.9 & 93.6 & 94.3 \\
\hline Avoid touching face & $1849(72.8)$ & $1301(72.0)$ & 75.5 & 73.6 & 75.3 & 73.5 \\
\hline Cough or sneeze into a tissue & $2169(85.4)$ & $1526(84.4)$ & 86.2 & 86.2 & 85.5 & 87.2 \\
\hline Wore facemask & $2508(98.7)$ & $1790(99.1)$ & 98.6 & 99.4 & 98.6 & 99.4 \\
\hline Cleaned common areas & $1871(73.6)$ & $1363(75.4)$ & 74.8 & 77.2 & 75.5 & 76.6 \\
\hline Avoid contact with sick people & $2430(95.6)$ & $1743(96.5)$ & 96.1 & 96.9 & 96.1 & 96.9 \\
\hline Kept 6 feet distance & $2400(94.5)$ & 1709 (94.6) & 94.7 & 94.9 & 94.8 & 95.1 \\
\hline Avoid large groups of people & $2374(93.4)$ & $1729(95.7)$ & 93.0 & 96.1 & 93.1 & 96.3 \\
\hline
\end{tabular}


Table 1. (continued)

\begin{tabular}{|c|c|c|c|c|c|c|}
\hline & \multicolumn{2}{|l|}{$N(\%)$} & \multicolumn{2}{|c|}{$\begin{array}{l}\text { Weighted \% without } \\
\text { IPTW* }\end{array}$} & \multicolumn{2}{|c|}{ Weighted \% with IPTW } \\
\hline & $\begin{array}{l}\text { TM enrollees } \\
(N=\mathbf{2 4 1 2})\end{array}$ & $\begin{array}{l}\text { MA enrollees } \\
(N=1545)\end{array}$ & $\begin{array}{l}\text { TM } \\
\text { enrollees }\end{array}$ & $\begin{array}{l}\text { MA } \\
\text { enrollees }\end{array}$ & $\begin{array}{l}\text { TM } \\
\text { enrollees }\end{array}$ & $\begin{array}{l}\text { MA } \\
\text { enrollees }\end{array}$ \\
\hline Shelter in place & $1924(75.7)$ & $1416(78.4)$ & 73.3 & 76.5 & 74.7 & 74.8 \\
\hline Buy extra food & $935(36.8)$ & $662(36.6)$ & 38.1 & 37.8 & 38.3 & 37.4 \\
\hline Buy extra cleaning supplies & $1468(57.8)$ & $1043(57.7)$ & 59.4 & 59.8 & 59.3 & 59.2 \\
\hline Buy extra medicines & $153(6.0)$ & $139(7.7)$ & 6.7 & 7.5 & 6.7 & 6.7 \\
\hline Consult with medical provider & $520(20.5)$ & $404(22.4)$ & 21.3 & 22.7 & 21.5 & 22.0 \\
\hline Avoid other people & $2230(87.8)$ & $1610(89.1)$ & 87.4 & 89.0 & 87.8 & 88.8 \\
\hline \multicolumn{7}{|l|}{ Perceptions of COVID-19 severity ${ }^{\S}$} \\
\hline $\begin{array}{l}\text { Agree that COVID-19 is more } \\
\text { contagious than flu }\end{array}$ & $2200(86.6)$ & $1603(88.7)$ & 86.2 & 88.7 & 86.5 & 88.0 \\
\hline $\begin{array}{l}\text { Agree that COVID-19 is more deadly } \\
\text { than flu }\end{array}$ & $2185(86.0)$ & $1586(87.8)$ & 85.3 & 87.7 & 85.7 & 86.4 \\
\hline $\begin{array}{l}\text { Agree that all should take COVID-19 } \\
\text { precautions }\end{array}$ & $2482(97.7)$ & 1779 (98.5) & 97.3 & 98.5 & 97.3 & 98.4 \\
\hline \multicolumn{7}{|l|}{ Vaccine uptake } \\
\hline $\begin{array}{l}\text { Would get a COVID-19 vaccine if } \\
\text { available }\end{array}$ & $1656(65.2)$ & $1121(62.0)$ & 64.0 & 61.5 & 63.4 & 62.6 \\
\hline
\end{tabular}

TM, traditional Medicare; MA, Medicare Advantage; IPTW, inverse probability of treatment weighting; COVID-19, coronavirus disease 2019; COPD, chronic obstructive pulmonary disease

*We used sampling weights provided by the Medicare Current Beneficiary Survey data

†To account for differences in characteristics between TM and MA enrollees attributable to selection bias, we computed the IPTW as a propensity for enrolling in MA based on enrollee demographic, socioeconomic, health status variables, as well as the primary source of COVID-19 information and the date of interview

Includes television, radio, websites, and/or newspapers

${ }^{3}$ Beneficiaries were asked to rate the following statements using a 5-point scale: "Coronavirus is more contagious than the flu," "Coronavirus is more deadly than the flu," and "it is important for everyone to take precautions to prevent the spread of the Coronavirus, even if they are not in a high-risk group." We categorized into two levels: agreed (strongly agree or agree) or not (neither agree nor disagree, disagree, or strongly disagree)

"Beneficiaries were asked to rate their answers on a 5-point scale, which we categorized into two levels: yes (definitely or probably) or no (not sure, probably not, or definitely not)

Table 2 Differences in Preventable Health Behaviors, Perceptions of COVID-19 Severity, and Likelihood of Getting a COVID-19 Vaccine if Available Between TM and MA Enrollees

\begin{tabular}{|c|c|c|c|}
\hline \multirow[t]{2}{*}{ Outcome } & \multicolumn{3}{|c|}{ Adjusted rates, \% (95\% CI) * } \\
\hline & TM enrollees & MA enrollees & $\begin{array}{l}\text { Differences among MA enrollees } \\
\text { relative to TM enrollees }\end{array}$ \\
\hline \multicolumn{4}{|l|}{ Preventable health behaviors } \\
\hline Wash hands & $97.0(96.2$ to 97.7$)$ & $97.1(96.2$ to 97.9$)$ & $0.1(-1.0$ to 1.3$)$ \\
\hline Use sanitizer & 93.7 (92.6 to 94.7$)$ & $94.2(93.1$ to 95.4$)$ & $0.6(-1.0$ to 2.2$)$ \\
\hline Avoid touching face & 75.3 (73.5 to 77.2$)$ & 73.5 (71.2 to 75.9$)$ & $-1.8(-4.8$ to 1.2$)$ \\
\hline Cough or sneeze into a tissue & $85.5(83.8$ to 87.1$)$ & 87.3 (85.6 to 89.0$)$ & $1.8(-0.6$ to 4.1$)$ \\
\hline Wore facemask & $98.6(98.0$ to 99.1$)$ & 99.3 (98.9 to 99.7$)$ & $0.8(0.1$ to 1.4$)$ \\
\hline Cleaned common areas & 75.5 (73.6 to 77.3$)$ & $76.6(74.4$ to 78.8$)$ & $1.2(-1.7$ to 4.0$)$ \\
\hline Avoid contact with sick people & $96.0(95.2$ to 96.9$)$ & 96.9 (96.0 to 97.8$)$ & $0.9(-0.4$ to 2.1$)$ \\
\hline Kept 6 feet distance & 94.8 (93.8 to 95.8$)$ & $95.0(93.9$ to 96.2$)$ & $0.2(-1.3$ to 1.7$)$ \\
\hline Avoid large groups of people & 93.1 (91.9 to 94.3$)$ & 96.3 (95.3 to 97.2$)$ & $3.1(1.6$ to 4.7$)$ \\
\hline Shelter in place & 74.7 ( 72.7 to 76.6$)$ & $74.8(72.4$ to 77.1$)$ & $0.1(-2.9$ to 3.2$)$ \\
\hline Buy extra food & $38.3(36.1$ to 40.6$)$ & $37.4(34.8$ to 39.9$)$ & $-1.0(-4.4$ to 2.4$)$ \\
\hline Buy extra cleaning supplies & $59.4(57.2$ to 61.6$)$ & $59.1(56.5$ to 61.8$)$ & $-0.3(-3.7$ to 3.2$)$ \\
\hline Buy extra medicines & $6.8(5.5$ to 8.0$)$ & $6.7(5.5$ to 7.9$)$ & $-0.1(-1.8$ to 1.7$)$ \\
\hline Consult with medical provider & $21.5(19.6$ to 23.4$)$ & 22.0 (19.8 to 24.2$)$ & $0.5(-2.4$ to 3.4$)$ \\
\hline Avoid other people & $87.9(86.4$ to 89.4$)$ & 88.7 (87.0 to 90.4$)$ & $0.8(-1.5$ to 3.1$)$ \\
\hline \multicolumn{4}{|l|}{ Perceptions of COVID-19 severity ${ }^{\dagger}$} \\
\hline Agree that COVID- 19 is more contagious than flu & $86.6(85.0$ to 88.2$)$ & $88.0(86.2$ to 89.7$)$ & $1.4(-1.0$ to 3.7$)$ \\
\hline Agree that COVID-19 is more deadly than flu & $85.7(84.1$ to 87.4$)$ & $86.4(84.5$ to 88.3$)$ & $0.6(-1.9$ to 3.1$)$ \\
\hline Agree that all should take COVID-19 precautions & $97.2(96.4$ to 98.1$)$ & $98.4(97.8$ to 99.1$)$ & $1.2(0.1$ to 2.3$)$ \\
\hline \multicolumn{4}{|l|}{ Vaccine uptake } \\
\hline Would get a COVID-19 vaccine if available & $63.3(61.1$ to 65.5$)$ & $62.7(60.1$ to 65.3$)$ & $-0.7(-4.1$ to 2.8$)$ \\
\hline
\end{tabular}

TM, traditional Medicare; MA, Medicare Advantage; IPTW, inverse probability of treatment weighting; COVID-19, coronavirus disease 2019

*To account for differences in characteristics between TM and MA enrollees attributable to selection bias, we computed the IPTW as a propensity for enrolling in MA based on enrollee demographic, socioeconomic, and health status variables as well as the primary source of COVID-19 information and the date of interview. Next, we estimated the mean adjusted values of the outcomes for TM and MA enrollees. We examined the difference in these adjusted mean outcomes among MA enrollees relative to TM enrollees

Beneficiaries were asked to rate the following statements using a 5-point scale: "Coronavirus is more contagious than the flu," "Coronavirus is more deadly than the flu," and "it is important for everyone to take precautions to prevent the spread of the Coronavirus, even if they are not in a high-risk group." We categorized into two levels: agreed (strongly agree or agree) or not (neither agree nor disagree, disagree, or strongly disagree)

$\ddagger$ Beneficiaries were asked to rate their answers on a 5-point scale, which we categorized into two levels: yes (definitely or probably) or no (not sure, probably not, or definitely not) 
with prior research that found that MA enrollees did not necessarily have higher primary care utilization than TM enrollees. ${ }^{5}$ There may be several explanations for our finding. First, current policies have mainly focused on COVID-19 testing and treatment. Thus, MA plans may not necessarily provide information campaigns aimed at reducing the risk of contracting COVID-19 compared to TM. Second, Medicare beneficiaries may have already had sufficient knowledge about COVID-19 through news media. As shown in our study, the majority reported their primary sources of COVID-19 information as traditional news sources, possibly leading to less reliance on information campaigns provided by their plans. The findings should be interpreted within several limitations. First, we could not adjust for unobserved differences in TM and MA enrollees. Second, we relied on relatively small samples. Third, we applied sample weights to produce population estimates, but this may not universally reflect experiences of Medicare beneficiaries.

Sungchul Park, $P h D^{1}$

Jeah Jung, $P h D^{2}$

Eric B. Larson, $M D, M P H^{3}$

${ }^{1}$ Department of Health Management and Policy, Dornsife School of Public Health, Drexel University,

Philadelphia, PA, USA

${ }^{2}$ Department of Health Policy and Administration, College of Health and Human Development, The Pennsylvania State University,

University Park, PA, USA
${ }^{3}$ Kaiser Permanente Washington Health Research Institute, Seattle, WA, USA

Corresponding Author: Sungchul Park, PhD; Department of Health Management and Policy, Dornsife School of Public Health, Drexel University, Philadelphia, PA, USA (e-mail: smp462@drexeledu).

\section{Declarations:}

Conflict of Interest: The authors declare that they do not have a conflict of interest.

\section{REFERENCES}

1. Jacobson $\mathbf{M}$, Thunell $\mathbf{J}$, Zissimopoulos $\mathbf{J}$. Cognitive assessment at Medicare's annual wellness visit in fee-for-service and Medicare Advantage plans. Health Aff (Millwood). 2020;39(11):1935-1942.

2. Centers for Medicare and Medicaid Services. MCBS Public Use File https://www.cms.gov/Research-Statistics-Data-and-Systems/Downloadable-Public-Use-Files/MCBS-Public-Use-File. Revised January 15, 2021. Accessed March 11, 2021.

3. Newhouse JP, Price M, McWilliams JM, Hsu J, Souza J, Landon BE. Adjusted mortality rates are lower for Medicare Advantage than traditional Medicare, but the rates converge over time. Health Aff (Millwood). 2019;38(4):554-560.

4. Park S, Jung J, Burke RE, Larson EB. Trends in use of low-value care in traditional fee-for-service Medicare and Medicare Advantage. JAMA Network Open. 2021;4(3):e211762.

5. Park S, Figueroa JF, Fishman P, Coe NB. Primary care utilization and expenditures in traditional Medicare and Medicare Advantage, 2007-2016. J Gen Intern Med. 2020;35(8):2480-2481.

Publisher's Note: Springer Nature remains neutral with regard to jurisdictional claims in published maps and institutional affiliations. 